\title{
Modeling and Simulation Based on the Intelligent On-shore Controlling Circulation Current Technology
}

\author{
Ye Wei-qiang ${ }^{1, ~ a ~}$, Xiao Le-min ${ }^{2, b}$ \\ 1,2 Department of Engineering , Guangzhou Maritime Institute, Guangzhou, 510725,China \\ aywqgmc@sina.com bxIm201@sina.com
}

\begin{abstract}
Keywords: On-Shore Controlling Circulation Current, Uninterruptable Power, Shore Power Connection
\end{abstract}

\begin{abstract}
The goal of this dissertation is to realize intelligent on-shore controlling circulation current. The mathematical model was built. And the simulation waveforms and transition and phasor analysis, etc. were given by using MATLAB software. The results show that the circulation current can be limited when shore power connected access to the ship power grid, and the effect of average voltage control and automatic synchronization can be accomplished; meanwhile circuit breaker operating current can be controlled by the circulation current of value and time when marine generators started access to shore power.
\end{abstract}

\section{Introduction}

On-shore controlling circulation current technology can achieve continuous power supply ${ }^{[1]}$ between the port and ship. With the reactor connected, to control inrush circulation current can be as a result of voltage difference and frequency difference and phase difference between transformer and generator, as well as, complete the average voltage and automatic synchronization of the generator by using finite circulation current, so as to take shore power into the marine generators power grid and exit generators board ship; when marine generators of the grid into shore grid, with impact circulation current controlling circuit breaker to trip, and with the reactor connected, as well as, complete current limit and the average voltage and automatic synchronization, so as to take the on-shore power into the generator power grid and trip from on-shore power. Basically unchanging the ship power station, berthing ships in harbor generally realize uninterruptable power connection quickly and readily with low-cost.

The technological core is as follows: Determining tripping current and time by the inrush circulation current variation with the control reactor connected to the circuit breaker when generators started access to shore power system; Building mathematical modeling by using the various parameters of transformers in actual harbor and marine generators on the berthing ships under the condition of the ultimate state and sudden change of load ${ }^{[3]}$. The goal of this paper is to realize intelligent on-shore controlling circulation current ${ }^{[4]}$. The mathematical model was built. And the simulation waveforms and transition and phasor analysis, etc. were given by using MATLAB software. The results show that the circulation current can be limited when shore power connected access to the ship power grid, and the effect of average voltage control and automatic synchronization can be accomplished; meanwhile circuit breaker operating current can be controlled by the circulation current of value and time when marine generators started access to shore power ${ }^{[5]}$.

\section{Circulation Current of the Average Voltage and automatic synchronization}

Circulation current of generator with average voltage function: the generator voltage is lower than the voltage transformer voltage, the circulation current make the generator produces increases the magnetoelectric armature reaction the voltage increases, the generator voltage is higher than the transformer voltage, demagnetization lower voltage. circulation current of generator with automatic synchronization function: the generator voltage phase advance transformer voltage phase (or frequency of the former is higher than the latter), the circulation current generator in the power 
generation state, the shaft by the braking force slow down; Phase lag (or frequency of the former is lower than the latter), the generator In a state of electric, shaft driving force to accelerate.
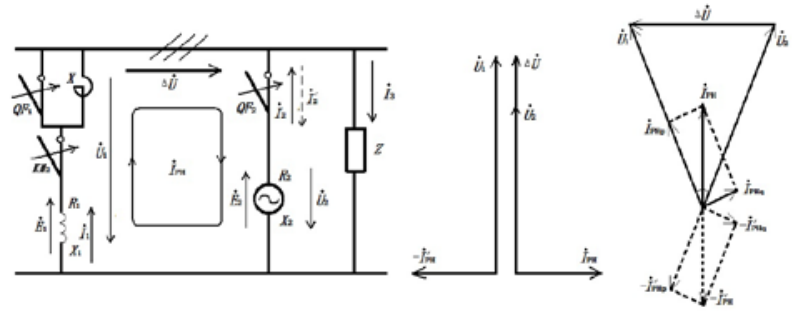

Fig.1 The average voltage and automatic synchronization of transformer and generator in parallel circulation current

As shown in Fig.1: $E_{1}$ stands for transformer of electric potential; $E_{2}$ potential for generator; In the phasor diagram $\mathrm{X}$ current is limited and consequently shorted, the circulation current of average voltage increase $U_{2}$ value, the voltage of transformer is equal to that of generator, the circulation current of automatic synchronization make the generator accelerate, frequency between transformer and generator are equal and in phase, so as to meet the conditions in parallel.

\section{Maximum of circulation current}

$$
\begin{aligned}
& \dot{U}_{1}=\dot{U}_{2}+\Delta \dot{U} \\
& \dot{E}+\dot{I}_{1}\left(R_{1}+j X_{1}\right)=\dot{E}+\dot{I}_{2}\left(R_{2}+j X_{2}\right)+\Delta \dot{U} \\
& \dot{I}_{1}=\dot{I}_{P H}+\dot{I}_{3} \\
& \dot{I}_{P H}=-\dot{I}_{2}
\end{aligned}
$$

When $I_{3}=0, \quad I_{1}=I_{\mathrm{PH}}, \quad R_{1}<<X_{1}, \quad R_{2}<<X_{2}, \quad E_{1} \approx E_{2}, \quad \varphi=\psi_{1}-\psi_{2}=\pi . \Rightarrow$ When $\Delta U=2 U_{N}$, maximum of circulation current is as follows: When $I_{3}=0, I_{1}=I_{\mathrm{PH}}, R_{1}<<X_{1}, R_{2}<<X_{2}, E_{1} \approx E_{2}$, $\varphi=\psi_{1}-\psi_{2}=\pi . \Rightarrow$ When $\Delta U=2 U_{N}$, maximum of circulation current is as follows:

$$
I_{P H} \approx \frac{2 U_{N}}{X_{1}+X_{2}}
$$

To limit circulation current of reactance estimate value

$$
\begin{gathered}
\dot{E}_{1}+\dot{I}_{1}\left(R_{1}+j X_{1}\right)+\dot{I}_{1} j X=\dot{E}_{2}+\dot{I}_{2}\left(R_{2}+j X_{2}\right)+\Delta \dot{U} \\
X=\frac{\dot{E}_{2}+\dot{I}_{2}\left(R_{2}+j X_{2}\right)+\Delta \dot{U}-\dot{E}_{1}-\dot{I}_{1}\left(R_{1}+j X_{1}\right)}{\dot{I}_{1}}
\end{gathered}
$$

$I_{1}=I_{2}=I_{\mathrm{PH}}, \quad R_{1}<<X_{1}, \quad R_{2}<<X_{2}, \quad E_{1} \approx E_{2}$, the relay action value for generators reverse power protection is $-5 \% \sim-15 \%$, if $I_{\mathrm{PH}}<5 \% I_{\mathrm{N}}$, formula(7) above is calculated as follow:

$$
X \approx X_{2}-X_{1}+\frac{2 U_{N}}{5 \% I_{N}}
$$




\section{Transient voltage differential between the generator and the transformer producing circulation current}

The function of voltage difference is as follows: The function of voltage difference is as follows:

$$
\begin{aligned}
& u=u_{1}-u_{2}=U_{1} \sin \left(\omega_{1} t+\psi_{1}\right)-U_{2} \sin \left(\omega_{2} t+\psi_{2}\right) \\
& \mathrm{U} 1=\mathrm{U} 2=\mathrm{U} \\
& u=2 U \cos \left[\frac{1}{2}\left(\omega_{1} t+\omega_{2} t\right)+\frac{1}{2}\left(\psi_{1}+\psi_{2}\right)\right] \times \sin \left[\frac{1}{2}\left(\omega_{1} t-\omega_{2} t\right)+\frac{1}{2}\left(\psi_{1}-\psi_{2}\right)\right]
\end{aligned}
$$

Voltage difference consists of two parts, i.e. the high frequency sine and low-frequency cosine. Voltage difference consists of two parts, i.e. the high frequency sine and low-frequency cosine.

(Fig. 2 (a) (b) (c) (d) are four envolope curves of the voltage difference, which are plotted by using MATLAB software, and respectively are correspondent to four different solutions i.e. only $f$ is different, both $U$ and $f$ are different, only $\Psi$ is different, $U$ and $\mathrm{f}$ and $\Psi$ are all different. The standard of envelope curves is $400 \mathrm{~V} / 50 \mathrm{~Hz}$. To suppose that $\Delta U=10 \% U\left(U_{1}=440 \mathrm{~V}\right), \Delta f=0.5 \mathrm{~Hz}\left(f_{2}=49.5 \mathrm{~Hz}\right)$, $\Delta \varphi=\pi\left(\Psi_{1}=\pi / 2, \Psi_{2}=-\pi / 2\right)$, the range of transient voltage difference envelope is $0 \sim 1200 \mathrm{~V}(0 \sim$ $1.5 \times 2 U$ ), cycle of envelope is about $4 \mathrm{~s}$. If $\mathrm{U}$ is same and $\mathrm{f}$ is different, envelope curve will pass zero, circulation current is zero i.e. the point of successful parallel. (Fig. 2 (a) (b) (c) (d) are four envolope curves of the voltage difference, which are plotted by using MATLAB software, and respectively are correspondent to four different solutions i.e. only $f$ is different, both $U$ and $f$ are different, only $\Psi$ is different, $U$ and f and $\Psi$ are all different. The standard of envelope curves is $400 \mathrm{~V} / 50 \mathrm{~Hz}$. To suppose that $\Delta U=10 \% U\left(U_{1}=440 \mathrm{~V}\right), \Delta f=0.5 \mathrm{~Hz}\left(f_{2}=49.5 \mathrm{~Hz}\right), \Delta \varphi=\pi\left(\Psi_{1}=\pi / 2\right.$, $\left.\Psi_{2}=-\pi / 2\right)$, the range of transient voltage difference envelope is $0 \sim 1200 \mathrm{~V}(0 \sim 1.5 \times 2 U)$, cycle of envelope is about $4 \mathrm{~s}$. If $\mathrm{U}$ is same and $\mathrm{f}$ is different, envelope curve will pass zero, circulation current is zero i.e. the point of successful parallel.

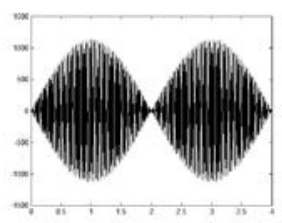

(a)

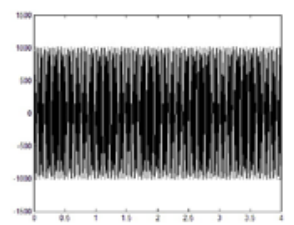

(c)

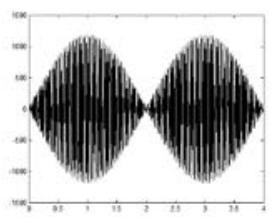

(b)

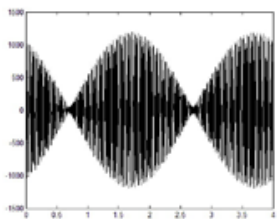

(d)

Fig. 2 The voltage difference curve of envelope

\section{With reactor connected breaker of action current and circulation current(QFb)}

$10 \mathrm{kV}$ transformer impedance voltage ratio is $4 \% \sim 6 \%$, and $100 \sim 1000 \mathrm{kVA}$ of that is $4.5 \% \sim 5 \%$, if it is $4 \%, I_{\mathrm{N}} \mathrm{Z}=4 \% U$, maximum short-circuit current $I_{\mathrm{d}}=U / \mathrm{z}=25 I_{\mathrm{N}}$, envelope transient maximum short-circuit current $i_{\mathrm{d}}=1.5 \times 25 I_{\mathrm{N}}$, transformer efficiency is $95 \% \sim 98 \%$, if it is $98 \%$, transformer iron loss is approximately equal to copper loss, as given below:

$$
2 \% I_{N}^{2} 2 \pi f=2 I_{N}^{2} R
$$


As shown in Fig.1: $E_{1}$ stands for transformer of electric potential; $E_{2}$ potential for generator; In the phasor diagram $\mathrm{X}$ current is limited and consequently shorted, the circulation current of average voltage increase $U_{2}$ value, the voltage of transformer is equal to that of generator, the circulation current of automatic synchronization make the generator accelerate, frequency between transformer and generator are equal and in phase, so as to meet the conditions in parallel.

To suppose the impedance of transformer is equal to that of the generator, circulation current is $I_{\mathrm{P}}=25 I_{\mathrm{N}} / 2=12.5 I_{\mathrm{N}}$, the expression of transient circulation current is as follows:

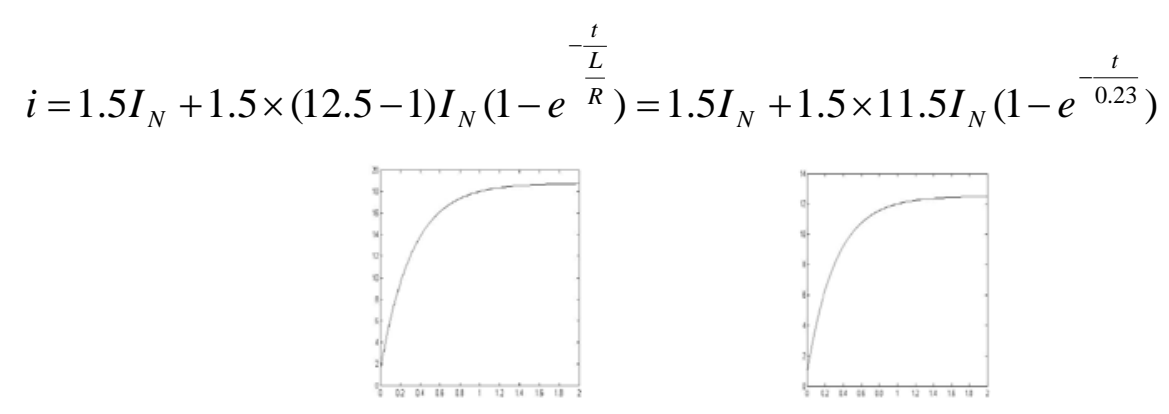

(a)

(b)

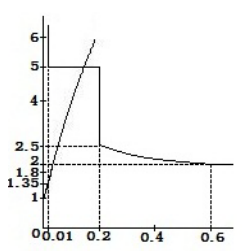

(c)

Fig.3 The circulation current and the circuit breaker operating current and time

Generators and shore power box circuit breaker (QFa) of transient circulation current is $200 \%$ $250 \% I_{\mathrm{N}}$, tripping after $0.2 \sim 0.6$ seconds delay, when more than 5 times $I_{\mathrm{N}}$, tripping after 0.01 second delay. After action time of $0.01 \mathrm{~s}$ is inserted into formula(14) above, $\mathrm{QFb}$ of transient circulation current is $i_{\mathrm{P}} \approx 202 \% I_{\mathrm{N}}$, and effective action current of envelope is $I_{\mathrm{Q}} \approx 202 \% I_{\mathrm{N}} / 1.5 \approx 135 \% I_{\mathrm{N}}$, setting $I=1.8 I_{\mathrm{N}}$ (in order to avoid mistrip due to inrush load), envelope correspond to the voltage difference is about $1200 \times 1.8 / 12.5 \approx 172.8 \mathrm{~V}, 0.01 \sim 0.2 \mathrm{~s}$ for shore power box circuit breaker is reliable action time range, Fig.3 (a) transient circulation current, and (b) effective circulation current, and (c) circuit breaker operating current vary with the time variable by using MATLAB simulation software.

\section{Circulation current and coordination between circuit breaker and reactor (Fig.4a)}

When $\mathrm{QFb}$ goes to maximum $5 I_{\mathrm{N}}$, tripping after $0.01 \mathrm{~s}$ delay, and meanwhile the circulation current decline in shore power box circuit breaker QFa transient circulation current is transient circulation current is $2.5 I_{\mathrm{N}}$, tripping after $0.2 \mathrm{~s}$ (see Fig. 4 c), the reactor $X_{\mathrm{L}}$ can be determined, as follow:

$$
I_{N}(5-1) e^{-\frac{0.2+0.045-t_{1}}{\frac{2 L+L_{x}}{2 R}}}+I_{N} \leq 2.5 I_{N}
$$

The estimation value of reactor $\mathrm{X}$ can be determined from formulas above, circulation current rising rate is $0.32 I_{\mathrm{N}} / 0.01 \mathrm{~s}$ (Fig.4 b), QFb of tripping value reduces to $4.68(4.5) I_{\mathrm{N}}$ to avoid QFa mistrip. Generators`current range is $1 \sim(4.5-1.8) I_{\mathrm{N}}$; three levels are as follows: $1 / 2.7 \sim 1 I_{\mathrm{N}}, 1 \sim 2.7 I_{\mathrm{N}}$, $2.7 \sim 2.7 \times 2.7 I_{\mathrm{N}}$; If $P_{\mathrm{N}}=100 \mathrm{~kW}$, the total capacity range is $37 \sim 729 \mathrm{~kW}$. If using hybrid current limiting circuit breaker for $\mathrm{QFb}$, circulation current rising rate $0.32 I_{\mathrm{N}} / 0.01 \mathrm{~s}<<\mathrm{QFb}$ action $18 \mathrm{~A} / \mu \mathrm{s}$, generator with power rating $500 \mathrm{~kW} I_{\mathrm{N}} \approx 1 \mathrm{kA}<\mathrm{QFb} 7.5 \mathrm{kA}, \mathrm{QFb}$ action time is $0.01 \mathrm{~s}>\mathrm{QFb} 1 \mathrm{~ms}$.

\section{Conclusion}

The actual problems are that in accordance to circulation current limit condition, the reactor can be chosen, but valve $\mathrm{X}$ is too high and the effect of motor synchronizing and average voltage control are both weak, which lead to generator reverse power trip, and failure. In this paper, these factors should be considered, i.e. the reactance value of actual marine generators and the actual transformer, impedance of cables for connecting the ships and shore, the possible impacts due to inrush load when 
paralleling. Then accurate mathematical models were established. The results show that the level and adapting range of reactor were determined, can be corrected by testing.

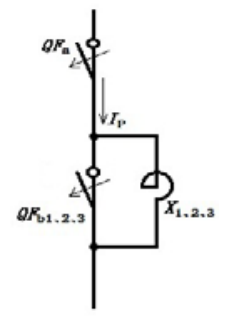

(a)

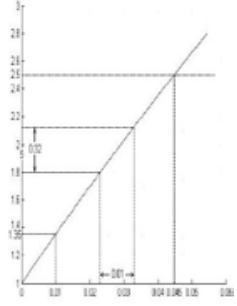

(b)

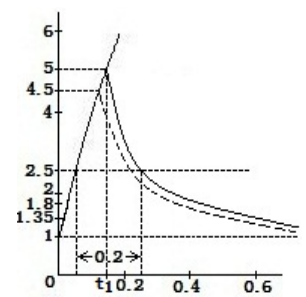

(c)

Fig.4 The simulation of ring current and circuit breaker together with reactor

\section{Acknowledgement}

In this paper, the research was sponsored by the scientific research project of Guangzhou in 2015 ( in general) and Science and technology innovation project of Guangdong Provincial Department of Education (2013KJCX0196).

\section{References}

[1] Bao Qifan. Research and application of on - shore powersupply system for vessel in port of Shanghai[J].Engineering Sciences, 2011(9): 63-68.

[2] ZHANG Guoqiao, MU Xin. Study on the shore power technology for green port construction, through investigating shore-side power for vessels in Lianyungang port [J]. Port Economy, 2011(1): 36-38.

[3] Ericsson P, Fazlagic I. Shore-side power supply[J]. Master of Science Thesis-Chalmers University of technology-Goteborg Sweden, 2008.

[4] CAO Shenghua, XU Dake, WANG Wenqiang, XU Gaowen. Implementation of integrated solution of intelligent shore power supply system [J]. Huadian Technology, 2011(11): 58.

[5] WANG Chen, ZHUANG Jinwu, JIANG Zhuangsian et al.Analysis of current limiting characteristics and commutation arc energy of improved hybrid current limiting circuit breake[J]. High Voltage Engineering, 2012 ( 6 ) : 1365-1371. 